\title{
Erratum to: Ecosystem Service Comparison before and after Marshland Conversion to Paddy Field in the Sanjiang Plain, Northeast China
}

\author{
Xiaohui Liu ${ }^{1,2} \cdot$ Ming Jiang ${ }^{1} \cdot$ Guihua Dong $^{3} \cdot$ Zhongsheng Zhang $^{1} \cdot$ Xigang Wang $^{4}$
}

Published online: 25 April 2017

(C) Society of Wetland Scientists 2017

\section{Erratum to: Wetlands}

DOI 10.1007/s13157-017-0894-4

The author would like to make the following correction

1. Page 6, "Soil Water Conservation Service The soil water conservation service of marshlands before conversion was $1.95 \times 10^{8} \mathrm{t}$ and $6.90 \times 10^{6} \mathrm{t}$ after conversion to paddy fields. The soil water conservation service value of marshlands before conversion was $0.13 \times 10^{9}$ Yuan and $4.62 \times 10^{6}$ Yuan after conversion to paddy fields.". They are all ok. But Line 13-14 in Abstract, "Soil water conservation value of marshlands before and after conversion was $0.13 \times 10^{9}$ Yuan and $0.02 \times 10^{9}$ Yuan, respectively.". During rounding number, $4.62 \times 10^{6}$ should be $0.005 \times 10^{9}$, not $0.02 \times 10^{9}$. It needs to revise and the following related operations are also need to modify.

2. Correspondingly, Line 21 in the abstract, "Overall, conversion of marshlands resulted in $0.57 \times 10^{9}$ Yuan of net

The online version of the original article can be found at http://dx.doi.10.1007 /s13157-017-0894-4

Xiaohui Liu

liuxh@iga.ac.cn

1 Key Laboratory of Wetland Ecology and Environment, Northeast Institute of Geography and Agroecology, CAS, Changchun 130102, China

2 State Key Laboratory of Lake Science and Environment, Nanjing Institute of Geography \& Limnology, CAS, Nanjing 210008, China

3 China National Environmental Monitoring Center, Beijing 100012, China

4 Changchun Huaxiang Faurecia Automotive Plastics Components Co., Ltd., Changchun 130015, China services loss.". Due to the revised of soil water conservation value of Marshlands-paddy, it was "Overall, conversion of marshlands resulted in $0.58 \times 10^{9}$ Yuan of net services loss.". Page 8 in the last paragraphs," $0.58 \times 10^{9}$ Yuan of net services loss".

3. Page 7 in this paragraph, "After marshlands conversion to paddy fields, the most important service provided by the marshlands-paddy was grain production, which was $54.1 \%$ of the total value. Next carbon budget was $45.1 \%$ of the total value. Soil water conservation service of marshlands before conversion was 6.5 times that of the marshlands-paddy." Due to the revised of soil water conservation value of Marshlands-paddy, "After marshlands conversion to paddy fields, the most important service provided by the marshlands-paddy was grain production, which was $54.3 \%$ of the total value. Next carbon budget was $45.3 \%$ of the total value. Soil water conservation service of marshlands before conversion was 26 times that of the marshlands-paddy". These numbers had been changed correspondingly. 